\title{
Design of UWB Planar Monopole Antennas with Etched Spiral Slot on the Patch for Multiple Band-Notched Characteristics
}

\author{
Swarup Das, Debasis Mitra, and Sekhar Ranjan Bhadra Chaudhuri \\ Department of Electronics \& Telecommunication Engineering, Indian Institute of Engineering Science and Technology, \\ Shibpur, Howrah 711 103, India \\ Correspondence should be addressed to Swarup Das; dasswarup08@yahoo.in
}

Received 7 June 2015; Revised 6 September 2015; Accepted 16 September 2015

Academic Editor: Mustapha C. E. Yagoub

Copyright (C) 2015 Swarup Das et al. This is an open access article distributed under the Creative Commons Attribution License, which permits unrestricted use, distribution, and reproduction in any medium, provided the original work is properly cited.

Three types of Ultrawideband (UWB) antennas with single, double, and triple notched bands are proposed and investigated for UWB communication applications. The proposed antennas consist of CPW fed monopole with spiral slot etched on the patch. In this paper single, double, and also triple band notches with central frequency of 3.57, 5.12, and $8.21 \mathrm{GHz}$ have been generated by varying the length of a single spiral slot. The proposed antenna is low-profile and of compact size. A stable gain is obtained throughout the operation band except the three notched frequencies. The antennas have omnidirectional and stable radiation patterns across all the relevant bands. Moreover, relatively consistent group delays across the UWB frequencies are noticed for the triple notched band antenna. A prototype of the UWB antenna with triple notched bands is fabricated and the measured results of the antenna are compared with the simulated results.

\section{Introduction}

In modern communication there has been increasing demand in designing Ultrawideband (UWB) systems [1]. The UWB radio system occupies UWB frequency band, that is, 3.1-10.6 GHz, approved by Federal Communications Commission (FCC) [2], in which there might potentially exist several narrow band interferences caused by other wireless communication systems, such as IEEE 802.11a wireless local area network (WLAN) in the frequency band of 5.15$5.35 \mathrm{GHz}$ and $5.725-5.825 \mathrm{GHz}$ and WiMAX mainly around $3.5 \mathrm{GHz}$. Therefore, it is necessary for UWB antennas to perform band-notched function in those frequency bands to avoid potential interferences. Recently, a number of antennas with band-notched property have been discussed in [3-15] and various methods have been used to achieve the function. The widely used methods are etching slots on the patch or on the ground plane, that is, C-shaped, H-shaped, L-shaped, U-shaped, V-shaped, arc-shaped, and pie-shaped slot [3-9]. Slot-type split ring resonators (SRRs) etched on the patch were found to have better performance in this regard [10,11]. Adding L-shaped and ring-shaped parasitic elements with suitable designs on the bottom of the substrate was another method to generate notched bands [12, 13]. Band-notched property has been realized in Ultrawideband monopole antennas by using a strip bar and a folded strip $[14,15]$.

Ultrawideband antenna with single notched band was reported in [16-18]; then different methods were applied to produce double band-notched function in Ultrawideband antennas [19-21]. Lately a number of recent techniques have been proposed to generate triple notched bands [22-25]. In [22] triple band notches are realized by adding closedloop ring in three different layers of the substrate. In [23] three open ended quarter-wavelength slots are used to obtain band-notched characteristics at three frequencies $3.5,5.5$, and $7.5 \mathrm{GHz}$. The triple band-notched characteristic is obtained by etching a complementary meander line split ring resonator inside the radiation patch and ground plane of a rectangular antenna in [24]. It is shown that the triple bandnotched performance at $3.31,5.81$, and $8.53 \mathrm{GHz}$ can be 
obtained. In [25] the antenna consists of a modified stair cased V-shaped radiating element and partial ground plane. The triple band-notched characteristics are achieved by embedding two different vertical up C-shaped slots with a vertical down $\mathrm{C}$-shaped slot in the radiating patch and in the ground plane, respectively. In [26] four notched bands were observed using four different metallic strips. Further in this structure using only three metallic strips four notched bands were obtained with some modification in the antenna geometry. Therefore to generate multiple band notches the above designs are complicated structures leading to increased fabrication costs, antenna size, and difficulty in the integration with microwave integrated circuits.

In this paper a single spiral slot has been used to generate single, double, and also triple notched bands by varying spiral slot length with central frequency of 3.57, 5.12, and $8.21 \mathrm{GHz}$, respectively. The main objective of this paper is to present a simple and compact realization with stable radiation performance of a triple band-notched planar antenna suitable for UWB applications. The notched characteristic is achieved in antenna using spiral-shaped slot etched on the radiating patch.

In the proposed structure UWB operation was obtained by using a simple rectangular patch. But in some other structures many complex techniques were used like beveling of patch and ground plane, using slit with matching steps and Defected Ground Structure (DGS) in [23, 24, 26], respectively. In [22-26] multiple notched bands were obtained using several metallic resonators or various types of slots while in the proposed structure multiple notched bands are found using a single spiral slot. In the proposed structure the spiral slot is etched on the single layer of patch which is much simpler to realize compared to the multilayered structure as described in [22]. Slots were etched on ground plane in [24, 25 ] to produce notched bands whereas ground plane is unaffected in the proposed structure. Some of the notched bandwidths are controlled to make them sharper in the proposed structure than the notched bandwidths given in [23-25].

The paper is organized into three main sections. The first section is concerned with the antenna that has single turn spiral slot etched on the patch to generate a single notched band. The second section deals with the spiral slot with two turns to achieve double notch bands and in the last section it is described that the spiral slot with three turns etched on the patch is used to achieve triple notch bands. All of these antennas with multiple notched bands are fabricated and experimentally verified.

\section{Spiral Slot Loaded Antenna with Single Notch}

The proposed structure of spiral slot loaded antenna with single notch is shown in Figure 1. The antenna is printed on the top of a lightweight FR4 $\left(\varepsilon_{r}=4.4, \tan \delta=0.02\right)$ substrate of thickness $h=1.6 \mathrm{~mm}$. The length $(L)$ and width $(W)$ of the substrate are $30 \mathrm{~mm}$ and $30 \mathrm{~mm}$, respectively. We optimize the antenna geometry for $S_{11}<-10 \mathrm{~dB}$ over the wideband frequency range. A symmetric slot has been etched on the patch which produced a single notch. The feed line is a $50 \Omega \mathrm{CPW}$

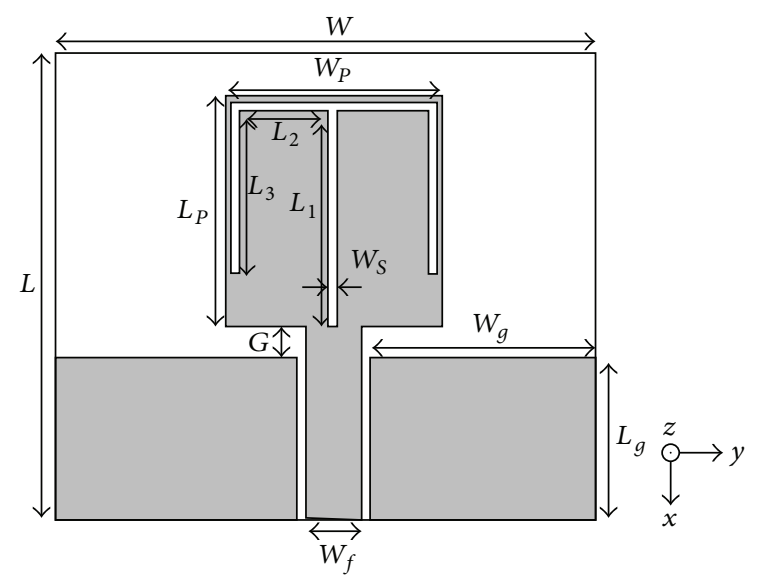

(a)

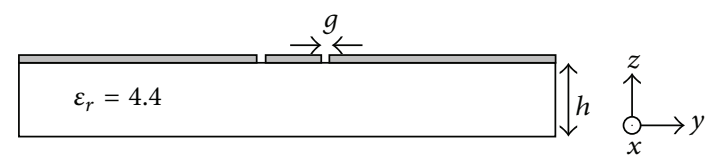

(b)

FIGURE 1: CPW fed planar monopole antenna with single notch: (a) top view, (b) side view.

line which is connected to the radiating element. For the design of the $50 \Omega \mathrm{CPW}$ feed line, the dimensions are chosen to be $W_{f}=3 \mathrm{~mm}$ and $g=0.3 \mathrm{~mm}$, where $W_{f}$ is the width of the feed line and $g$ is the gap between feed line and ground plane. The length $\left(L_{P}\right)$ and width $\left(W_{P}\right)$ of the radiating patch element are $12 \mathrm{~mm}$ and $10 \mathrm{~mm}$, respectively. The optimized value of gap between patch and ground plane is kept at $G=$ $1.7 \mathrm{~mm}$. Each of the ground planes has a size of $\left(L_{g} \times W_{g}\right)$ $\mathrm{mm}^{2}$ where $L_{g}=12.3 \mathrm{~mm}$ and $W_{g}=13.2 \mathrm{~mm}$. The spiralshaped slot etched on patch has a width of $W_{S}=0.5 \mathrm{~mm}$. The total length of the slot can be calculated as $L_{1}+2\left(L_{2}+L_{3}\right)=$ $11.25+2(4+8) \mathrm{mm}=27.25 \mathrm{~mm}$. To reject the interference with existing wireless band a thin spiral slot has been printed on the radiating patch as a half-guided wavelength resonator to generate the notched band. In our design, the spiral slot is etched with a width of $0.5 \mathrm{~mm}$ to produce stronger resonance that guarantees better band-rejected performance.

The simulated and measured return loss of the structure is shown in Figure 2. The simulation has been conducted using High Frequency Structure Simulator 11 (HFSS11). The reference antenna (without slot) exhibits a bandwidth of $7.84 \mathrm{GHz}$ $(10.80 \mathrm{GHz}-2.96 \mathrm{GHz})$. By using the Agilent N5230A network analyzer, $S_{11}$ has been measured. Measured result shows that a notched band is generated from $3.4 \mathrm{GHz}$ to $3.65 \mathrm{GHz}$.

\section{Spiral Slot Loaded Antenna with Double Notch}

On the same structure as described previously slot length has been increased $14 \mathrm{~mm}$ on both sides which gives dual notch. The gap between two slots is kept at $M_{S}=0.25 \mathrm{~mm}$. This structure has been shown in Figure 3. 


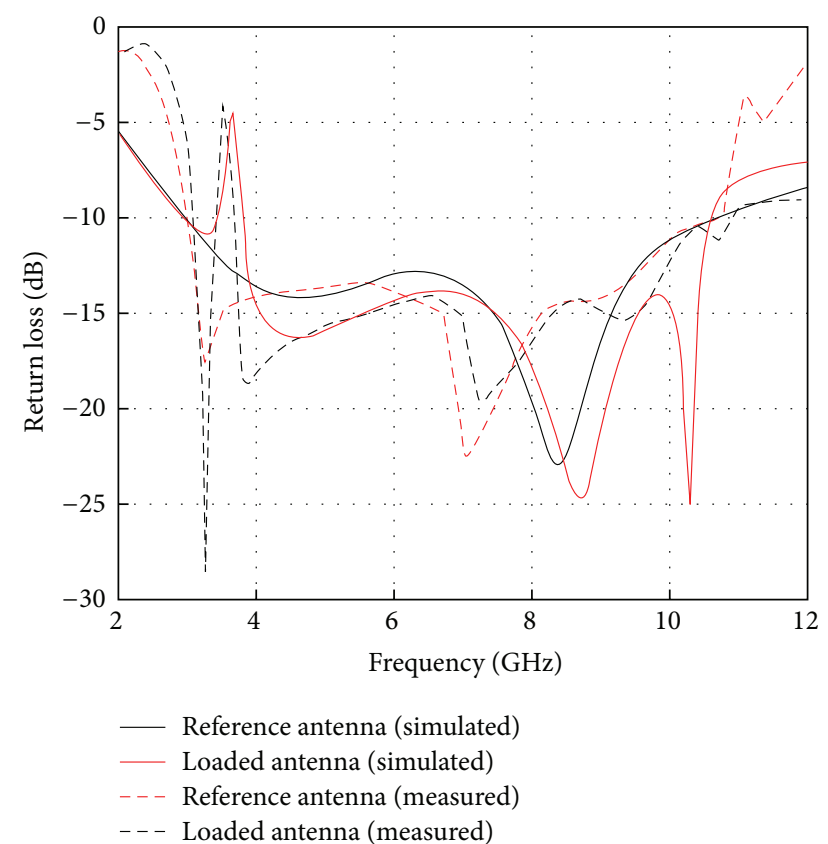

FIGURE 2: Return loss plot of the monopole antenna with single notch.

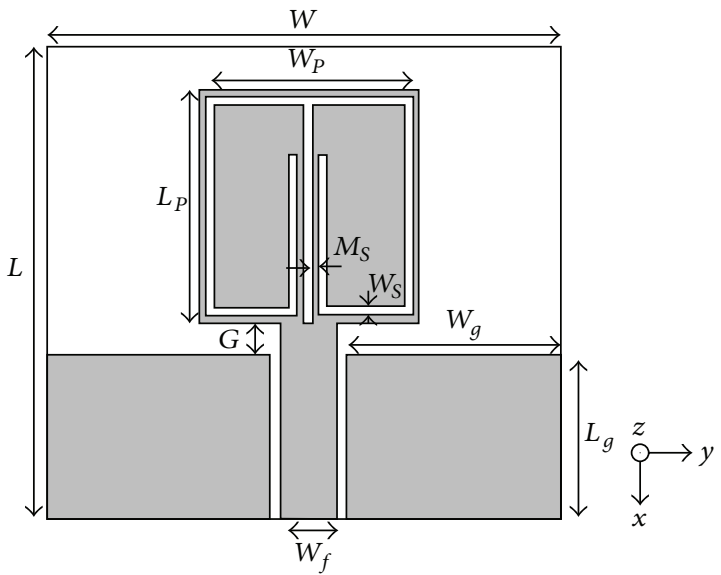

(a)

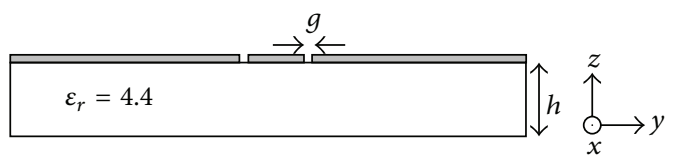

(b)

FIgURE 3: CPW fed planar monopole antenna with double notch: (a) top view, (b) side view.

The simulated and measured return loss of the structure is shown in Figure 4. The simulation has been conducted using High Frequency Structure Simulator 11 (HFSS11). By increasing the slot length two notched bands are obtained. By using the Agilent N5230A network analyzer, $S_{11}$ has been measured. Measured result shows that it has a bandwidth of $8.11 \mathrm{GHz}(11.05 \mathrm{GHz}-2.94 \mathrm{GHz})$ with two notched bands of $2.17 \mathrm{GHz}(5.97 \mathrm{GHz}-3.8 \mathrm{GHz})$ and $1.87 \mathrm{GHz}(10.07 \mathrm{GHz}-$ $8.2 \mathrm{GHz})$.

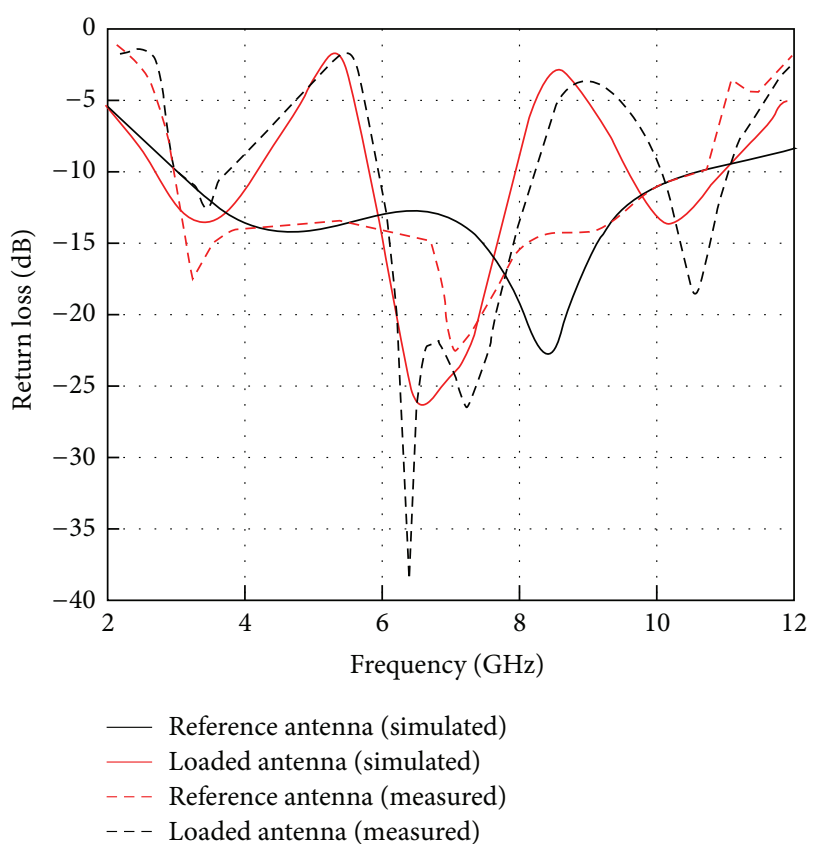

FIgURE 4: Return loss plot of the monopole antenna with double notch.

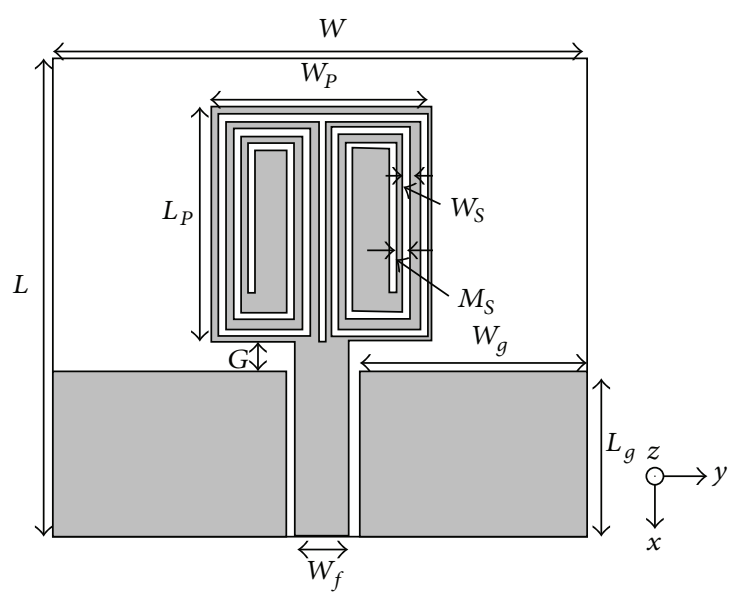

(a)

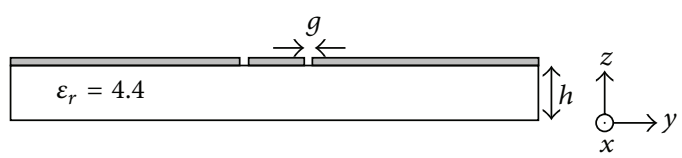

(b)

FIGURE 5: CPW fed planar monopole antenna with triple notch: (a) top view, (b) side view.

\section{Spiral Slot Loaded Antenna with Triple Notch}

Figure 5 shows that on the same structure as described previously (Figure 3) slot length has been increased $35.4375 \mathrm{~mm}$ on both sides. This increased slot length gives triple notch at desired frequencies. The gap between two slots is kept $M_{S}=$ $0.25 \mathrm{~mm}$. 


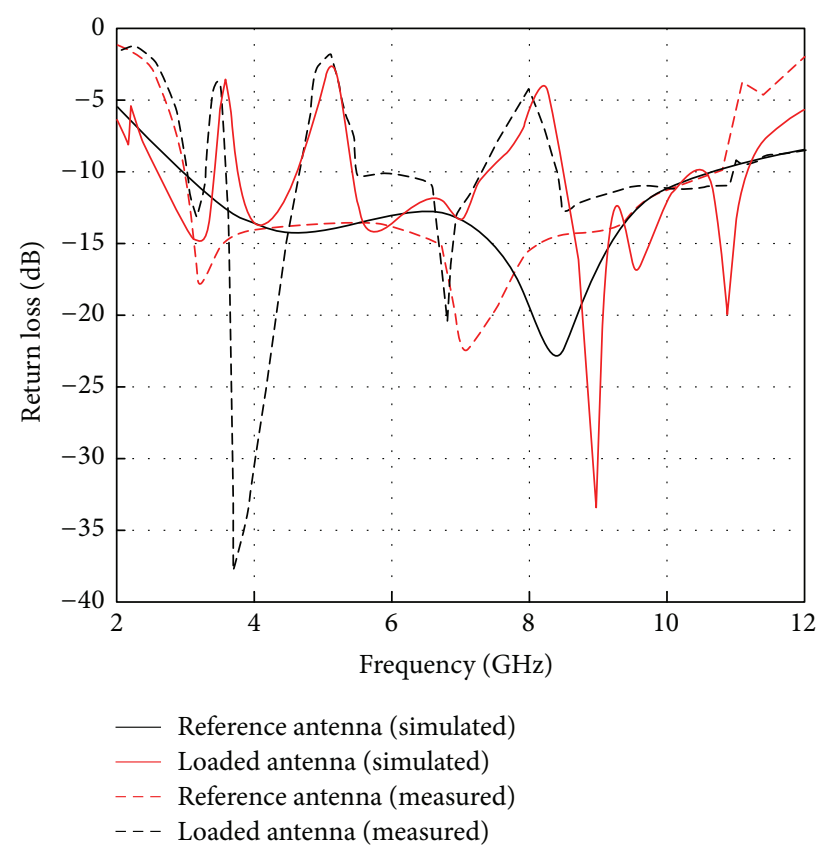

FIGURE 6: Return loss plot of monopole antenna with triple notch.

From simulated result we are getting a bandwidth of $8.57 \mathrm{GHz}$ covering frequency range from 2.59 to $11.16 \mathrm{GHz}$ shown in Figure 6. By using the Agilent N5230A network analyzer, $S_{11}$ has been measured. This result shows a bandwidth of $8.11 \mathrm{GHz}$, covering frequencies from 3.04 to $10.90 \mathrm{GHz}$ along with three notched bands of $0.32 \mathrm{GHz}$ (3.61 GHz-3.29 GHz), $0.84 \mathrm{GHz}(5.49 \mathrm{GHz}-4.65 \mathrm{GHz})$, and $1.11 \mathrm{GHz}(8.41 \mathrm{GHz}-7.3 \mathrm{GHz})$.

Generally speaking for getting the required notched bands the length of the slot is increased by increasing number of turns. The current distribution is not uniform on the surface of the patch; that is, it varies from center to the edge of the patch. By increasing number of turns of the slot this current distribution is affected in different way and also it introduces new capacitive and inductive loading effect. Therefore this slot is resonating at different frequencies for which the notched bands are obtained.

In order to further understand the behavior of the resonating structure, especially in the notched bands, surface current distribution at five different frequencies $3.57 \mathrm{GHz}$, $5.12 \mathrm{GHz}, 6 \mathrm{GHz}, 8.21 \mathrm{GHz}$, and $9 \mathrm{GHz}$ is simulated and displayed in Figures 7(a), 7(b), 7(c), 7(d), and 7(e), respectively. It is seen that the current distribution around spiral slot resonating structure increases drastically at $3.57 \mathrm{GHz}, 5.12$, and $8.21 \mathrm{GHz}$ which implies that the spiral slot resonates near $3.57 \mathrm{GHz}, 5.12$, and $8.21 \mathrm{GHz}$. Thus, from both the return loss characteristic and the simulated surface current distribution, it can be concluded that the spiral resonator generates the frequency notched function.
The $E$ plane $\left(\varphi=0^{\circ}\right.$ plane $)$ and $H$ plane $\left(\varphi=90^{\circ}\right.$ plane $)$ radiation patterns of the antenna structures are shown in Figure 8. The radiation patterns were measured in an anechoic chamber in the entire bandwidth. The radiation patterns in two planes at six different frequencies are shown in Figure 8. It is seen that this antenna has the nearly monopolelike, omnidirectional radiation pattern. It is observed that at higher frequencies the radiation pattern has tilted because of the fact that at higher frequency surface current distribution increases at ground plane.

The antenna gain is simulated and measured in the entire band. From Figure 9(a) it is found that gain decreases sharply in the notched frequency band. For other frequencies out of the notched frequency band, the antenna exhibits moderate gain. Sharp decrease in gain is observed at the three notched frequencies. The same type of result is obtained for radiation efficiency as shown in Figure 9(b). The efficiency decreases sharply at the notched bands and for other frequencies out of the notched band it shows reasonable values. Hence it can be concluded that the antenna is radiating effectively outside notched bands without great amount of losses due to surface waves.

The simulated and measured results of all the three structures are summarized in Table 1.

\section{Parametric Variation}

Figure 10(a) shows the variation of notch band frequency with respect to the gap between two slots $\left(M_{S}\right)$ and slot width $\left(W_{S}\right)$. Figure 10(b) shows the effects of the gap $(G)$ between 

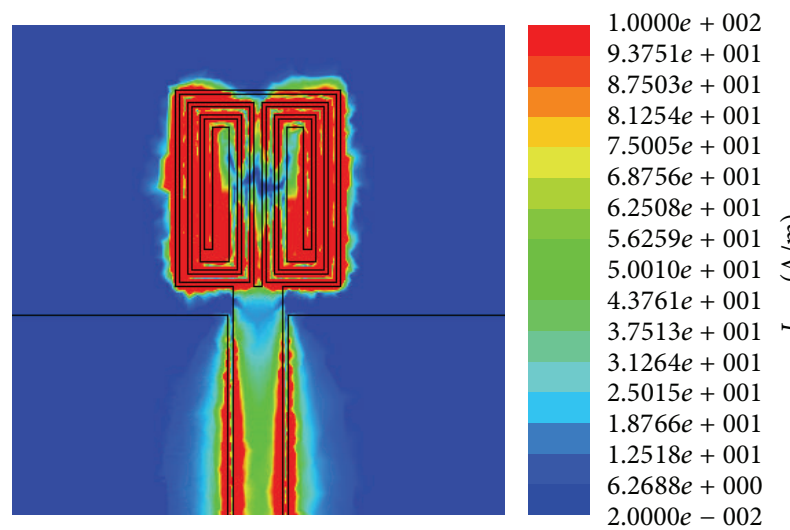

(a)
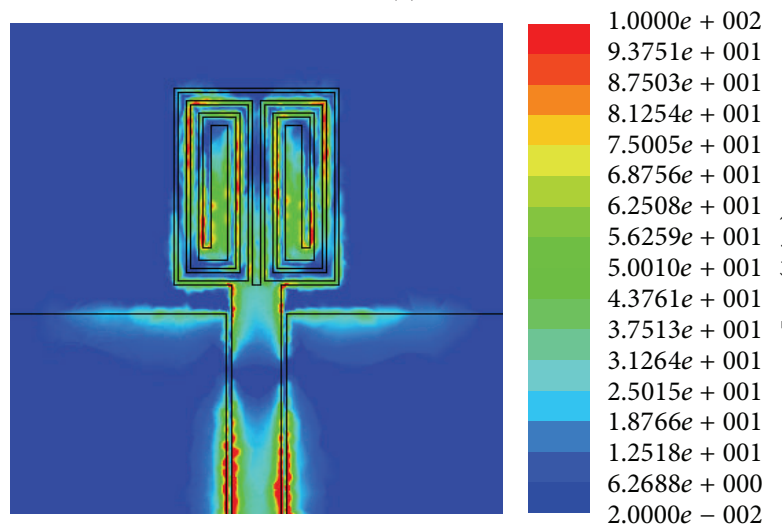

(c)

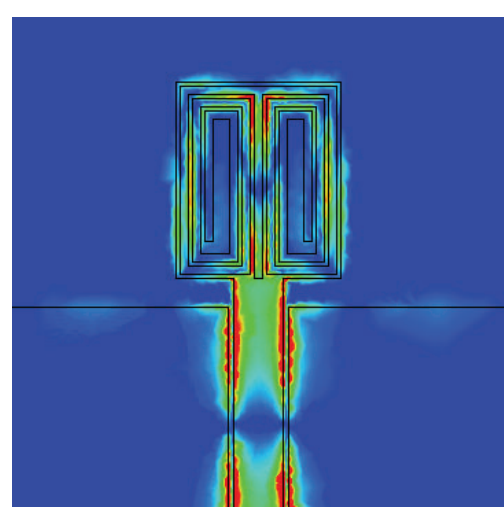

(e)
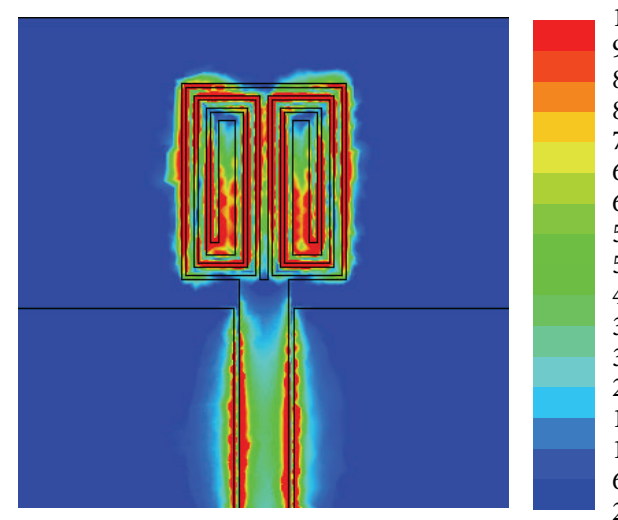

$1.0000 e+002$ $9.3751 e+001$ $8.7503 e+001$ $8.1254 e+001$ $7.5005 e+001$ $6.8756 e+001$ $6.2508 e+001$ $5.6259 e+001$ $5.0010 e+001 \varangle$ $4.3761 e+001$ $3.7513 e+001-$ $3.1264 e+001$ $2.5015 e+001$ $1.8766 e+001$ $1.2518 e+001$ $6.2688 e+000$ $2.0000 e-002$

(b)

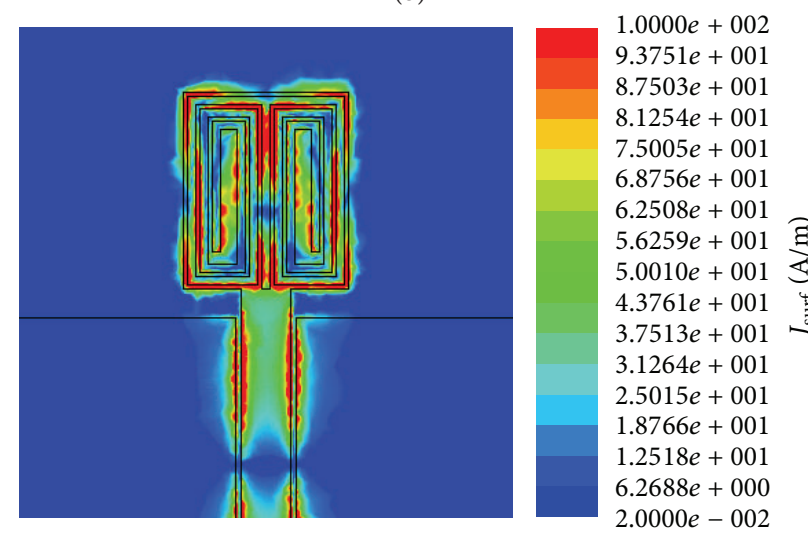

(d)

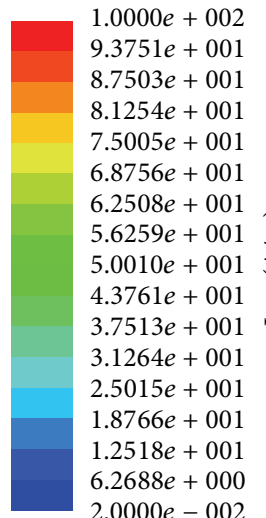

$1.0000 e+002$ $9.3751 e+001$ $8.7503 e+001$ $8.1254 e+001$ $7.5005 e+001$ $6.8756 e+001$ $6.2508 e+001$ $5.6259 e+001$ छ $5.0010 e+001 \mathbb{\Xi}$ $4.3761 e+001$ $3.7513 e+001$ $3.1264 e+001$ $2.5015 e+001$ $6.2688 e+000$ $2.0000 e-002$

FIGURE 7: Surface current distribution: (a) $3.57 \mathrm{GHz}$, (b) $5.12 \mathrm{GHz}$, (c) $6 \mathrm{GHz}$, (d) $8.21 \mathrm{GHz}$, and (e) $9 \mathrm{GHz}$.

TABLE 1: Simulated and measured notch frequency and notch bandwidth for three types of antenna.

\begin{tabular}{lcccc}
\hline $\begin{array}{l}\text { Antenna } \\
\text { type }\end{array}$ & \multicolumn{2}{c}{$\begin{array}{c}\text { Notch frequency } \\
\text { Simulated }\end{array}$} & \multicolumn{2}{c}{ Notch bandwidth } \\
Single & $3.66 \mathrm{GHz}$ & $3.52 \mathrm{GHz}$ & $3.40-3.80 \mathrm{GHz}$ & $3.40-3.65 \mathrm{GHz}$ \\
notch & & & & \\
\hline $\begin{array}{l}\text { Double } \\
\text { notch }\end{array}$ & $5.30 \mathrm{GHz}$ & $5.48 \mathrm{GHz}$ & $4.18-5.82 \mathrm{GHz}$ & $3.80-5.97 \mathrm{GHz}$ \\
\hline \multirow{2}{*}{$\begin{array}{l}\text { Triple } \\
\text { notch }\end{array}$} & $3.58 \mathrm{GHz}$ & $9.04 \mathrm{GHz}$ & $7.92-9.61 \mathrm{GHz}$ & $8.20-10.07 \mathrm{GHz}$ \\
\hline & $5.12 \mathrm{GHz}$ & $5.07 \mathrm{GHz}$ & $4.60-5.40 \mathrm{GHz}$ & $4.65-5.49 \mathrm{GHz}$ \\
& $8.21 \mathrm{GHz}$ & $7.98 \mathrm{GHz}$ & $7.30-8.53 \mathrm{GHz}$ & $7.30-8.41 \mathrm{GHz}$ \\
\hline
\end{tabular}

the monopole and ground plane. This gap can control the bandwidth of third notch. In this case, results show that the notched bandwidth for proposed antenna becomes wider when $G$ increases from $1.4 \mathrm{~mm}$ to $2 \mathrm{~mm}$.

In order to verify the capability of the proposed antenna to operate as UWB antenna, it is necessary to achieve a consistent group delay. The group delay properties of the proposed multiband antenna have been studied and results have been shown in Figure 11. The results show that the simulated group delay is flat with variations below $0.05 \mathrm{~ns}$ whereas measured group delay variations are below $1 \mathrm{~ns}$ which is acceptable. The fabricated proposed UWB antenna is shown in Figure 12. 

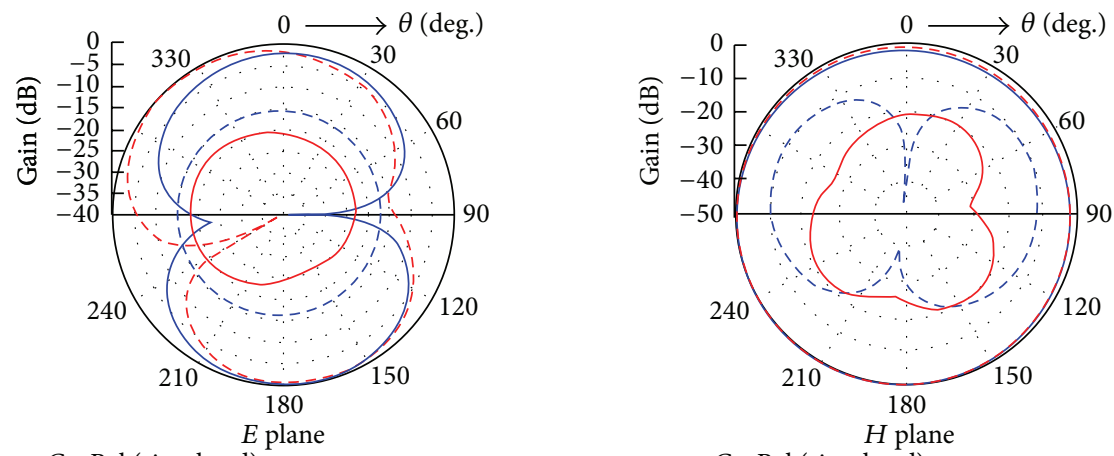

- Co-Pol (simulated) - - Co-Pol (measured)

Cross-Pol (simulated) - - - Cross-Pol (measured)

- Co-Pol (simulated) _ - - Co-Pol (measured)

- Cross-Pol (simulated) - - - Cross-Pol (measured)

(a)

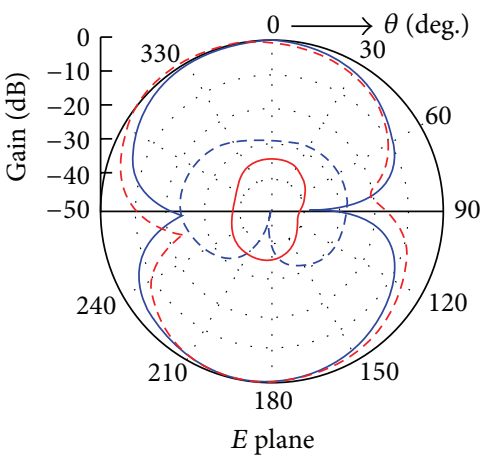

- Co-Pol (simulated) - - Co-Pol (measured)

— Cross-Pol (simulated) - - - Cross-Pol (measured)
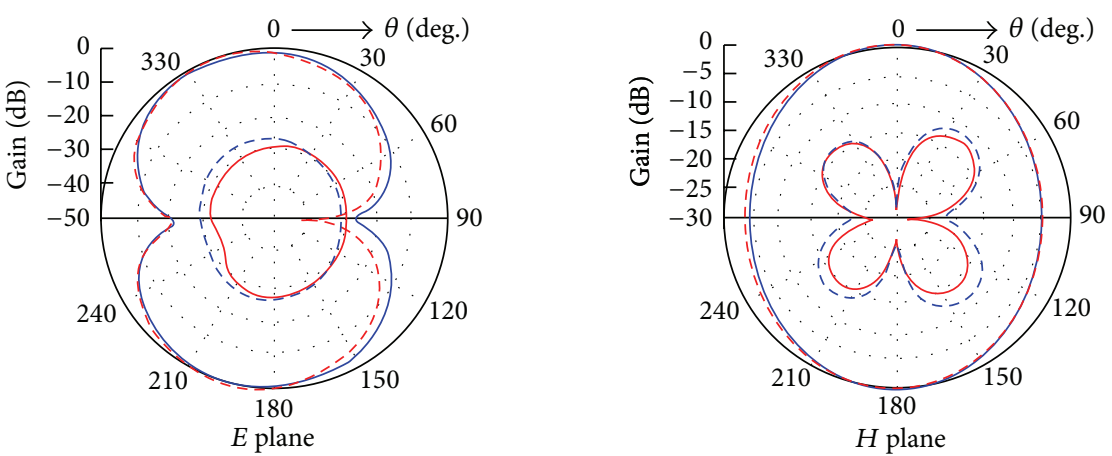

- Co-Pol (simulated) - - Co-Pol (measured)

Cross-Pol (simulated) - - - Cross-Pol (measured)

(c)

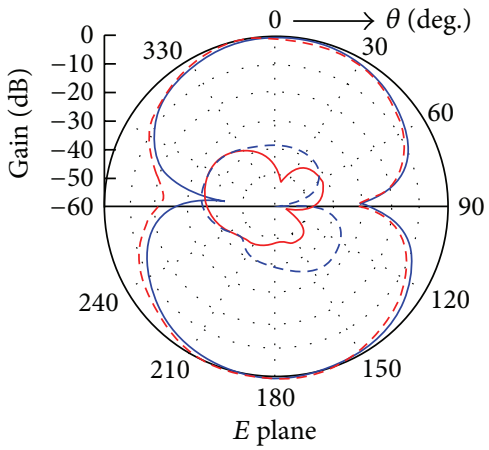

Co-Pol (simulated)

- - - Co-Pol (measured)

Cross-Pol (simulated) - - - Cross-Pol (measured)

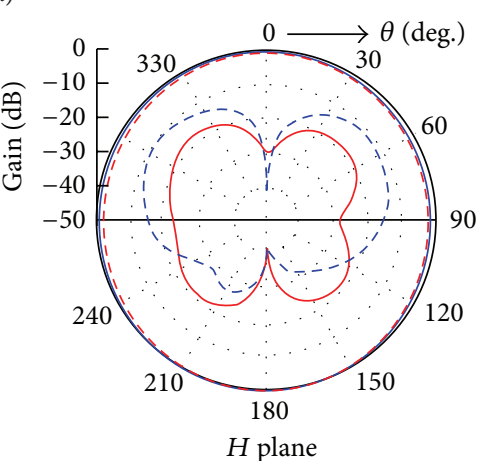

- Co-Pol (simulated) - - Co-Pol (measured)

Cross-Pol (simulated) - - - Cross-Pol (measured)
Co-Pol (simulated)
-- Co-Pol (measured)
Cross-Pol (simulated) - - - Cross-Pol (measured)

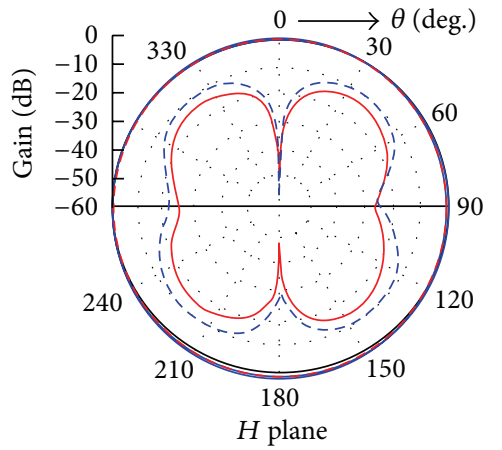

- Co-Pol (simulated) - - Co-Pol (measured)

(d)

Figure 8: Continued. 

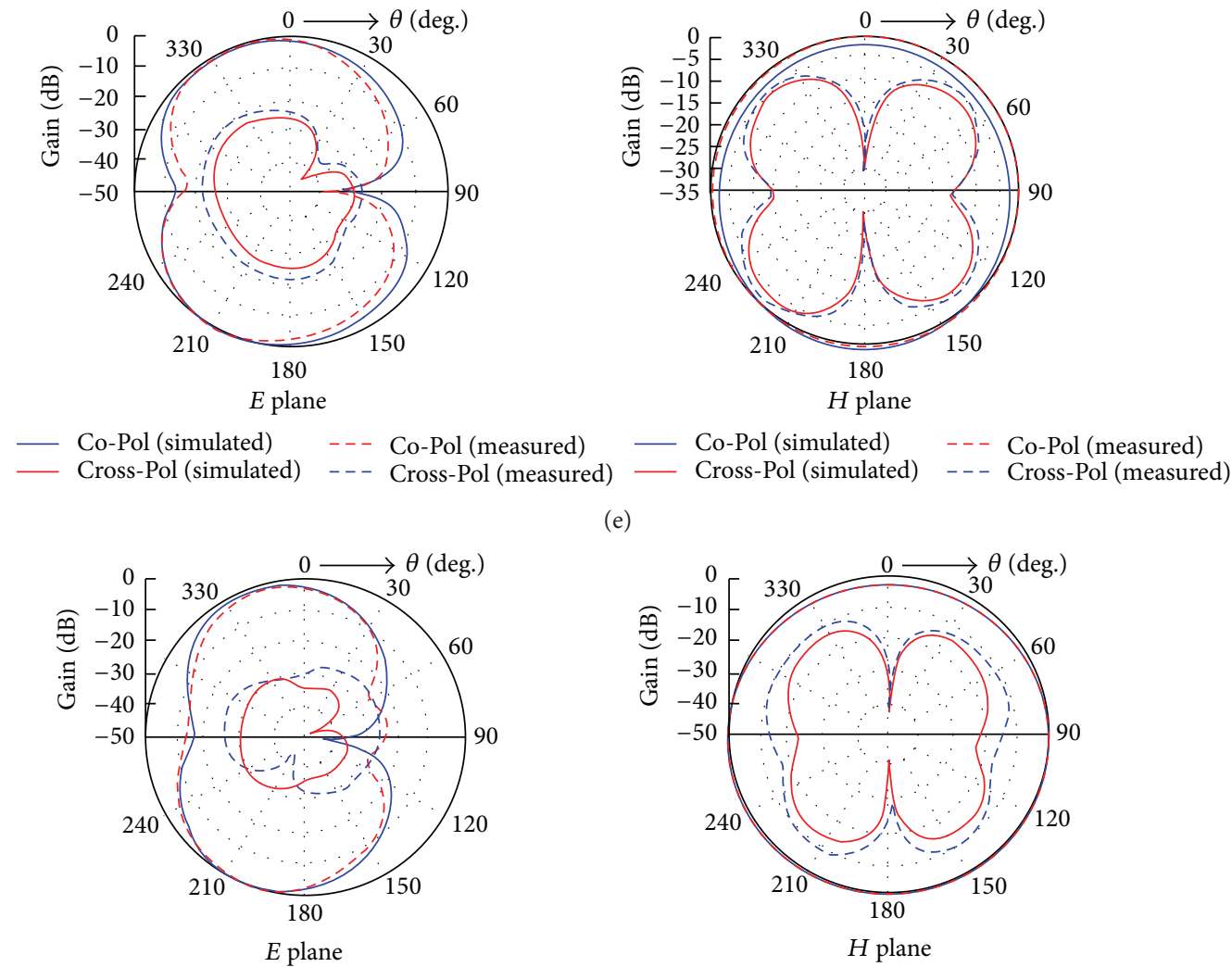

(e)
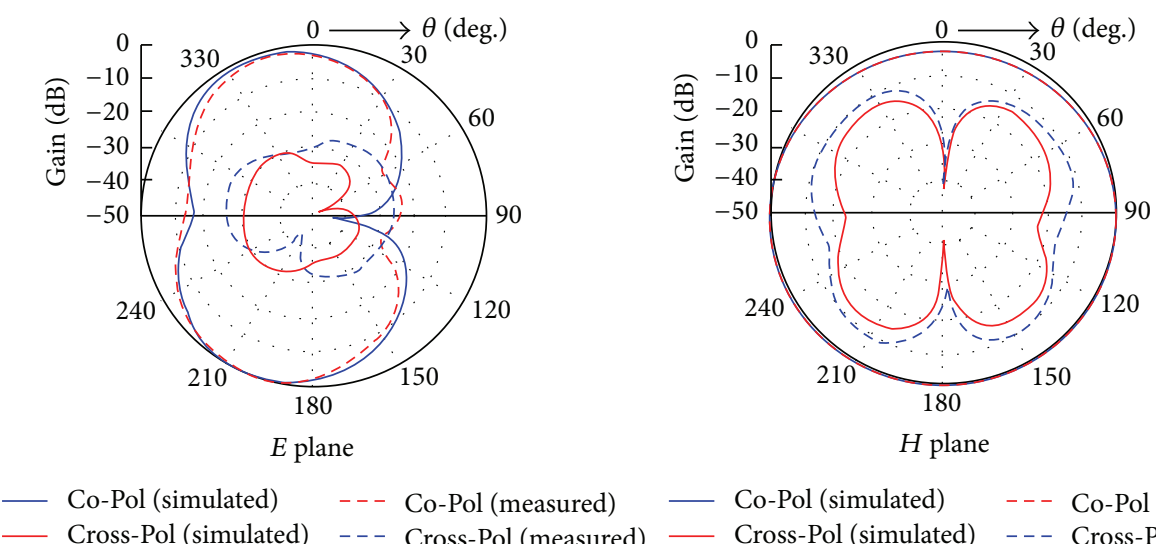

- Cross-Pol (simulated) - - - Cross-Pol (measured)

(f)

FIGURE 8: Simulated and measured normalized radiation pattern at various frequencies of (a) $3 \mathrm{GHz}$, (b) $3.57 \mathrm{GHz}$, (c) $5.12 \mathrm{GHz}$, (d) $6 \mathrm{GHz}$, (e) $8.21 \mathrm{GHz}$, and (f) $9 \mathrm{GHz}$.

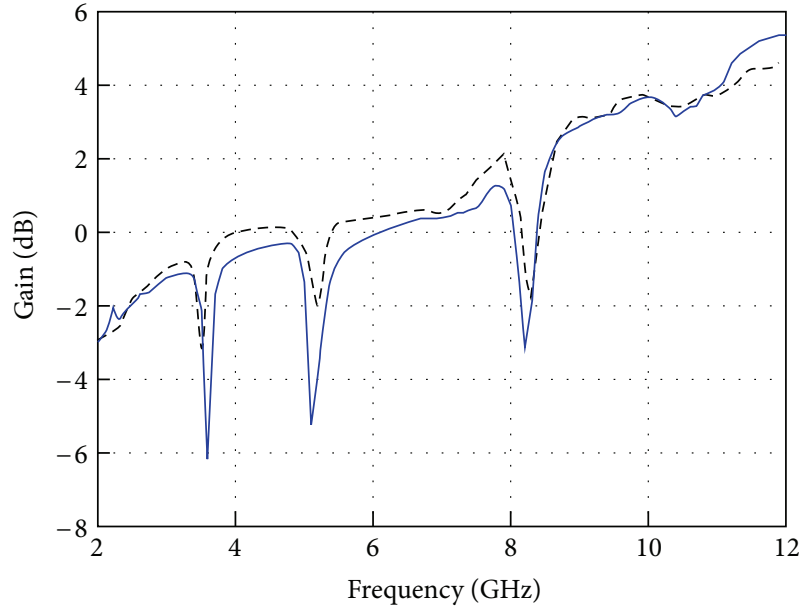

- - - Measured

- Simulated

(a)

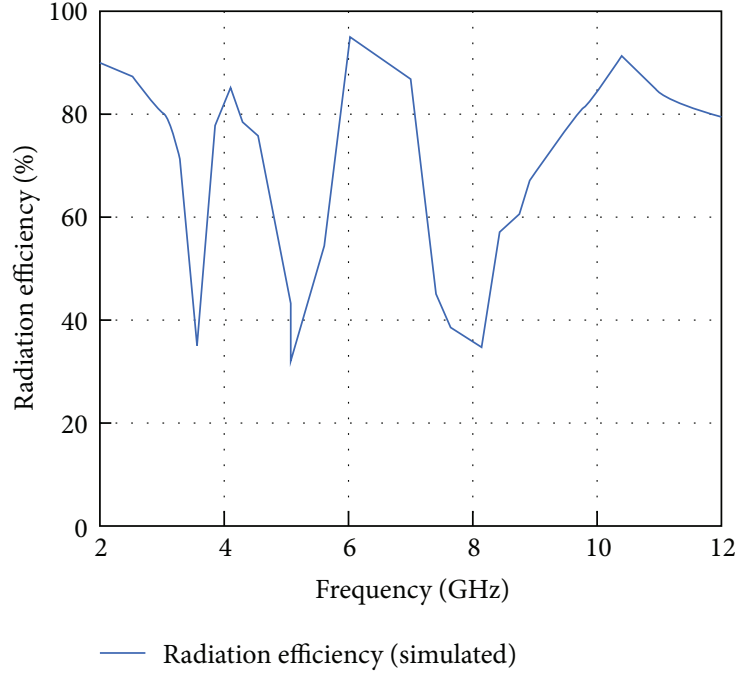

(b)

FIGURE 9: (a) Gain versus frequency plot of proposed UWB antenna with triple notch bands. (b) Radiation efficiency versus frequency plot of proposed UWB antenna with triple notch bands. 


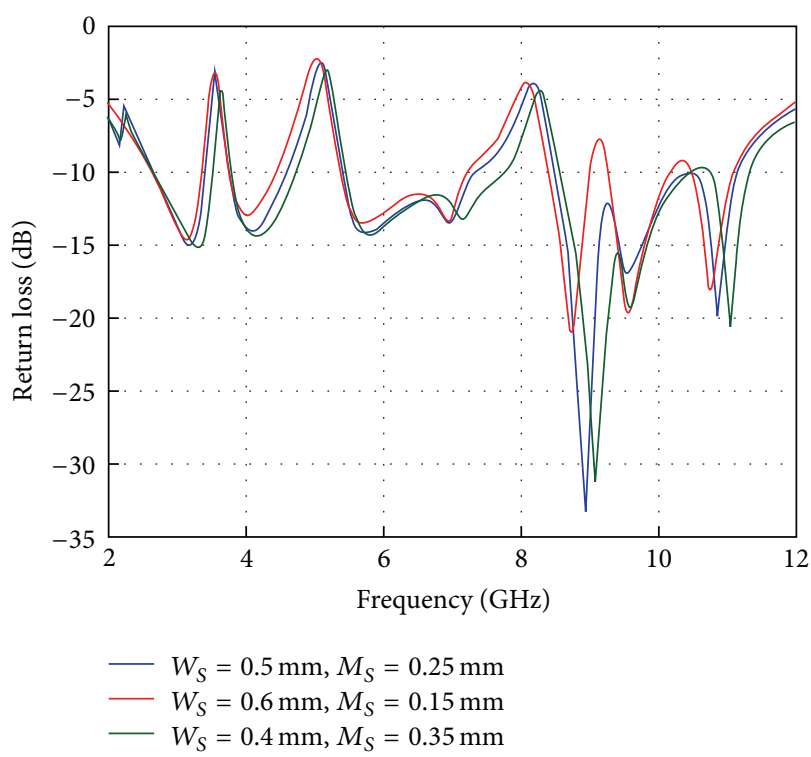

(a)

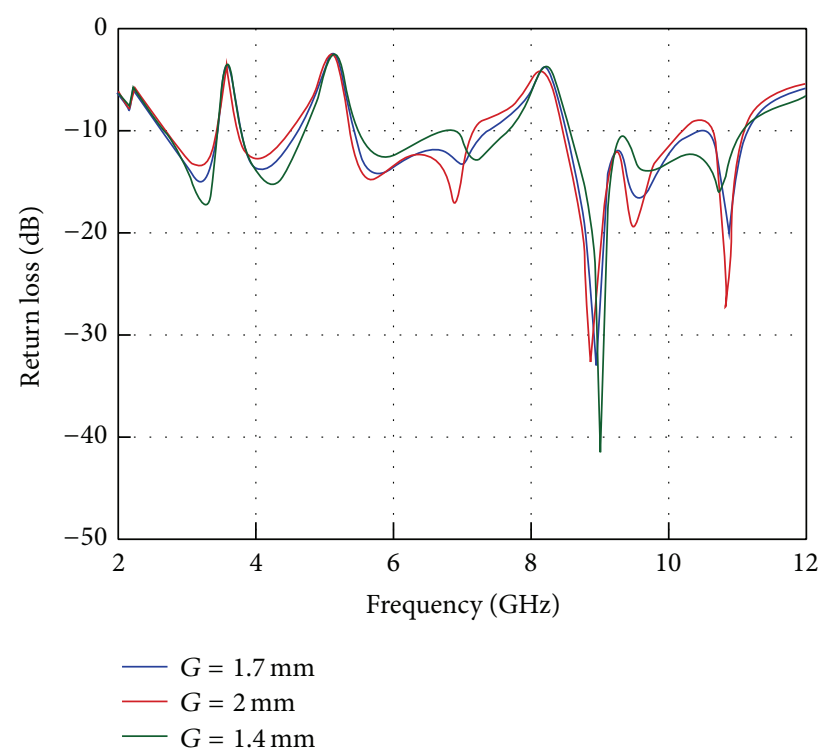

(b)

Figure 10: (a) Return loss plot for different values of $W_{S}, M_{S}$. (b) Return loss plot for different values of gap $(G)$.

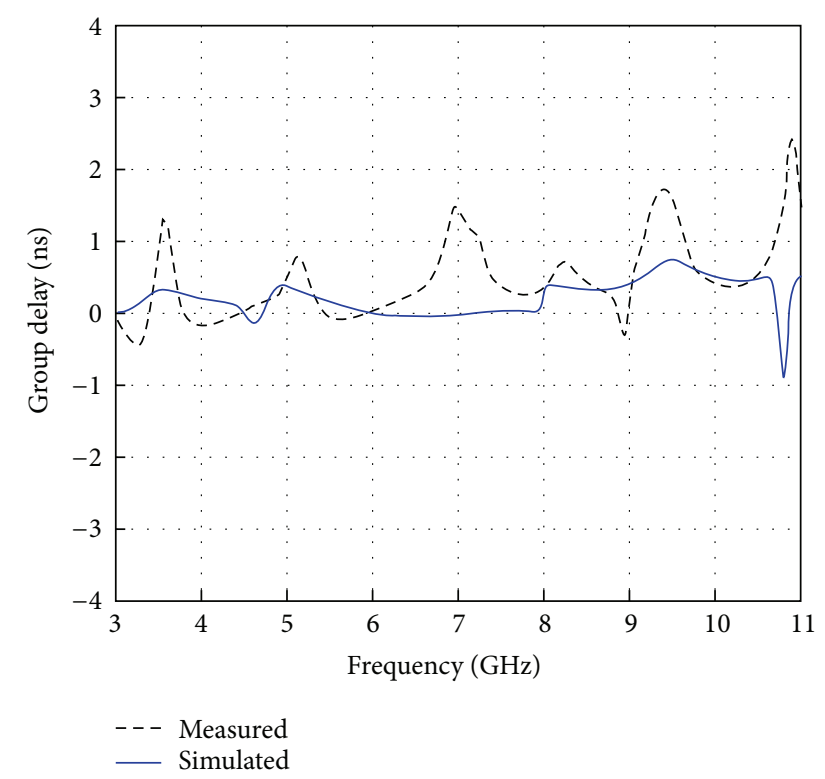

FIGURE 11: Group delay versus frequency plot.

\section{Conclusion}

A novel concept for design of compact UWB monopole antennas with variable single, double, and triple filtering function is proposed. By properly adjusting the length of the spiral slot single, double, and triple notched bands have been generated at WiMAX, WLAN, and satellite communication frequencies. It is also observed that the radiation patterns of the proposed antennas are nearly omnidirectional over the entire operating bandwidth as well as relatively consistent group delay across the UWB frequencies. Moreover, a stable

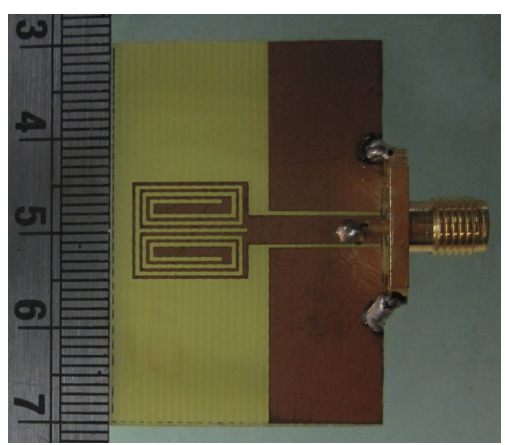

FIGURE 12: Fabricated photograph of the proposed antenna.

gain is obtained throughout the operation band except the three notched frequencies. The simulated results have been verified with the experimental results and are found to be in good agreement. The proposed multiple band-notched UWB antenna is low-profile, compact having simple structure, and easily compatible with microwave integrated circuits.

\section{Conflict of Interests}

The authors declare that there is no conflict of interests regarding the publication of this paper.

\section{References}

[1] I. Oppermann, M. Hämäläinen, and J. Iinatti, UWB Theory and Applications, chapter 1, John Wiley \& Sons, New York, NY, USA, 2004.

[2] Federal Communications Commission, "Revision of part 15 of the commission's rules regarding ultra-wideband transmission systems," First Report and Order FCC 02.V48, FCC, 2002. 
[3] Y. Kim and D.-H. Kwon, "CPW-fed planar ultra wideband antenna having a frequency band notch function," Electronics Letters, vol. 40, no. 7, pp. 403-405, 2004.

[4] K.-L. Wong, Y.-W. Chi, C.-M. Su, and F.-S. Chang, "Bandnotched ultra-wideband circular-disk monopole antenna with an arc-shaped slot," Microwave and Optical Technology Letters, vol. 45, no. 3, pp. 188-191, 2005.

[5] C.-Y. Huang and W.-C. Hsia, "Planar ultra-wideband antenna with a frequency notch characteristic," Microwave and Optical Technology Letters, vol. 49, no. 2, pp. 316-320, 2007.

[6] S. Barbarino and F. Consoli, "UWB circular slot antenna provided with an inverted-L notch filter for the $5 \mathrm{GHz}$ WLAN band," Progress in Electromagnetics Research, vol. 104, pp. 1-13, 2010.

[7] K. Chung, J. Kim, and J. Choi, "Wideband microstrip-fed monopole antenna having frequency band-notch function," IEEE Microwave and Wireless Components Letters, vol. 15, no. 11, pp. 766-768, 2005.

[8] W. Choi, K. Chung, J. Jung, and J. Choi, "Compact ultrawideband printed antenna with band-rejection characteristic," Electronics Letters, vol. 41, no. 18, pp. 990-991, 2005.

[9] W.-S. Lee, D.-Z. Kim, K.-J. Kim, and J.-W. Yu, "Wideband planar monopole antennas with dual band-notched characteristics," IEEE Transactions on Microwave Theory and Techniques, vol. 54, no. 6, pp. 2800-2805, 2006.

[10] J. C. Ding, Z. L. Lin, Z. N. Ying, and S. L. He, "A compact ultrawideband slot antenna with multiple notch frequency bands," Microwave and Optical Technology Letters, vol. 49, no. 12, pp. 3056-3060, 2007.

[11] J. Kim, C. S. Cho, and J. W. Lee, " $5.2 \mathrm{GHz}$ notched ultra-wideband antenna using slot-type SRR," Electronics Letters, vol. 42, no. 6, pp. 315-316, 2006.

[12] S.-H. Lee, J.-W. Baik, and Y.-S. Kim, "A coplanar waveguide fed monopole ultra-wideband antenna having band-notched frequency function by two folded-striplines," Microwave and Optical Technology Letters, vol. 49, no. 11, pp. 2747-2750, 2007.

[13] K.-H. Kim and S.-O. Park, "Design of the band-rejected UWB antenna with the ring-shaped parasitic patch," Microwave and Optical Technology Letters, vol. 48, no. 7, pp. 1310-1313, 2006.

[14] K. Chung, S. Hong, and J. Choi, "Ultrawide-band printed monopole antenna with band-notch filter," IET Microwaves, Antennas \& Propagation, vol. 1, no. 2, pp. 518-522, 2007.

[15] T.-G. Ma and S.-J. Wu, "Ultrawideband band-notched folded strip monopole antenna," IEEE Transactions on Antennas and Propagation, vol. 55, no. 9, pp. 2473-2479, 2007.

[16] M. Zhang, Y.-Z. Yin, J. Ma, Y. Wang, W.-C. Xiao, and X.-J. Liu, “A racket-shaped slot UWB antenna coupled with parasitic strips for band-notched application," Progress in Electromagnetics Research Letters, vol. 16, pp. 35-44, 2010.

[17] L. Lizzi, G. Oliveri, P. Rocca, and A. Massa, "Planar monopole UWB antenna with UNII1/UNII2 WLAN-band notched characteristics," Progress In Electromagnetics Research B, vol. 25, pp. 277-292, 2010.

[18] M. Xie, Q. Guo, and Y. Wu, "Design of a miniaturized UWB antenna with band-notched and high frequency rejection capability," Journal of Electromagnetic Waves and Applications, vol. 25, no. 8-9, pp. 1103-1112, 2011.

[19] G.-P. Gao, Z.-L. Mei, and B.-N. Li, "Novel circular slot UWB antenna with dual band-notched characteristic," Progress in Electromagnetics Research C, vol. 15, pp. 49-63, 2010.
[20] Y.-Q. Xia, J. Luo, and D.-J. Edwards, "Novel miniature printed monopole antenna with dual tunable band-notched characteristics for UWB applications," Journal of Electromagnetic Waves and Applications, vol. 24, no. 13, pp. 1783-1793, 2010.

[21] R. Shi, X. Xu, J. Dong, and Q. Luo, "Design and analysis of a novel dual band-notched UWB antenna," International Journal of Antennas and Propagation, vol. 2014, Article ID 531959, 10 pages, 2014.

[22] M. Almalkawi and V. Devabhaktuni, "Ultrawideband antenna with triple band-notched characteristics using closed-loop ring resonators," IEEE Antennas and Wireless Propagation Letters, vol. 10, pp. 959-962, 2011.

[23] D. T. Nguyen, D. H. Lee, and H. C. Park, "Very compact printed triple band-notched UWB antenna with quarter-wavelength slots," IEEE Antennas and Wireless Propagation Letters, vol. 11, pp. 411-414, 2012.

[24] J.-Y. Kim, B.-C. Oh, N. Kim, and S. Lee, "Triple band-notched UWB antenna based on complementary meander line SRR," Electronics Letters, vol. 48, no. 15, pp. 896-897, 2012.

[25] C. Abdelhalim and D. Farid, "A compact planar UWB antenna with triple controllable band-notched characteristics," International Journal of Antennas and Propagation, vol. 2014, Article ID 848062, 10 pages, 2014.

[26] V. M. Nangare and V. G. Kasabegoudar, "Ultra-wideband monopole antenna with multiple notch characteristics," International Journal of Electromagnetics and Applications, vol. 4, no. 3, pp. 70-76, 2014. 

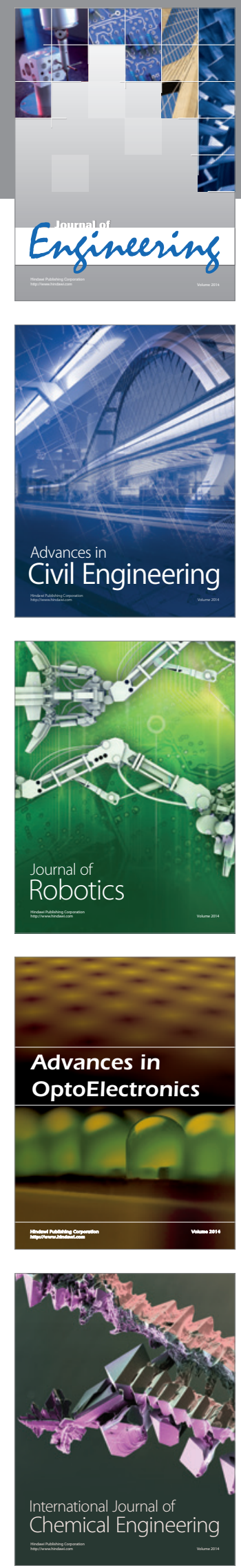

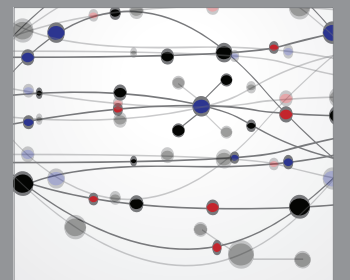

The Scientific World Journal
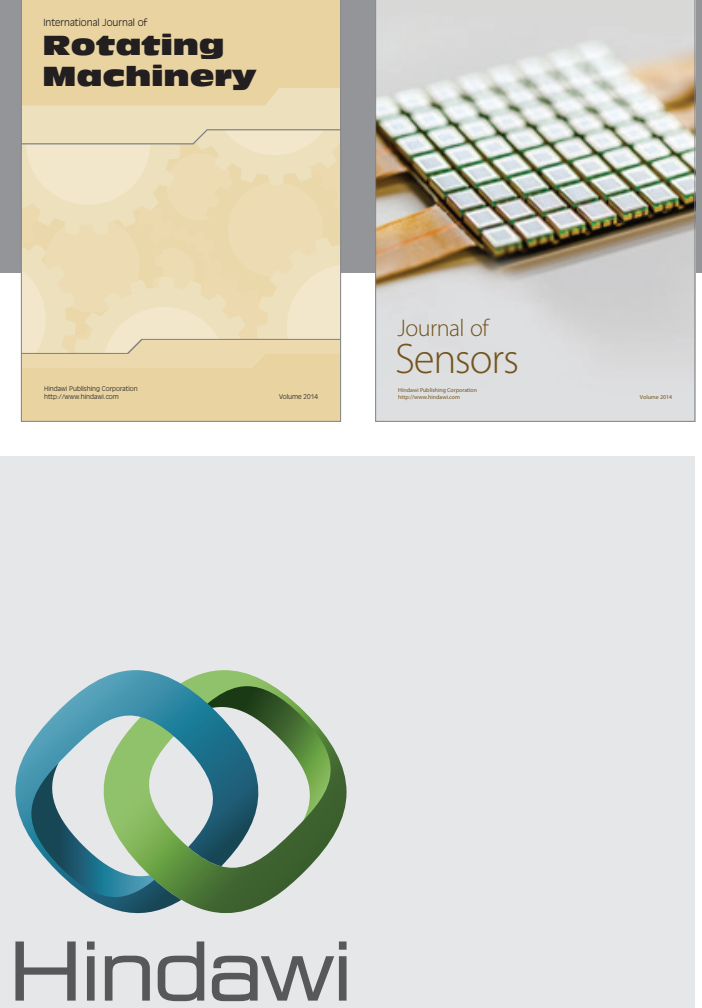

Submit your manuscripts at http://www.hindawi.com
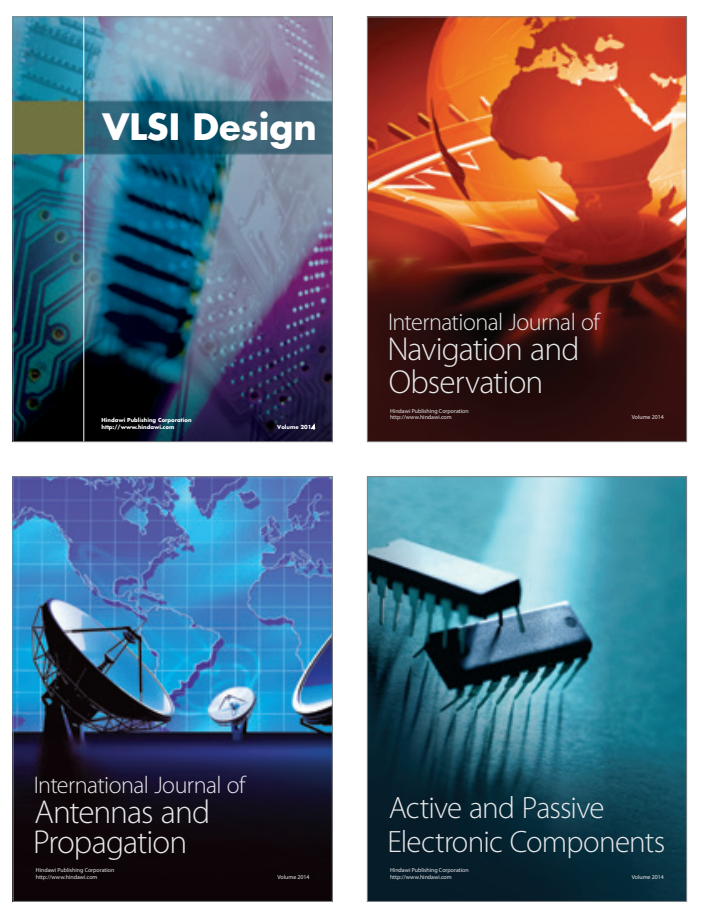
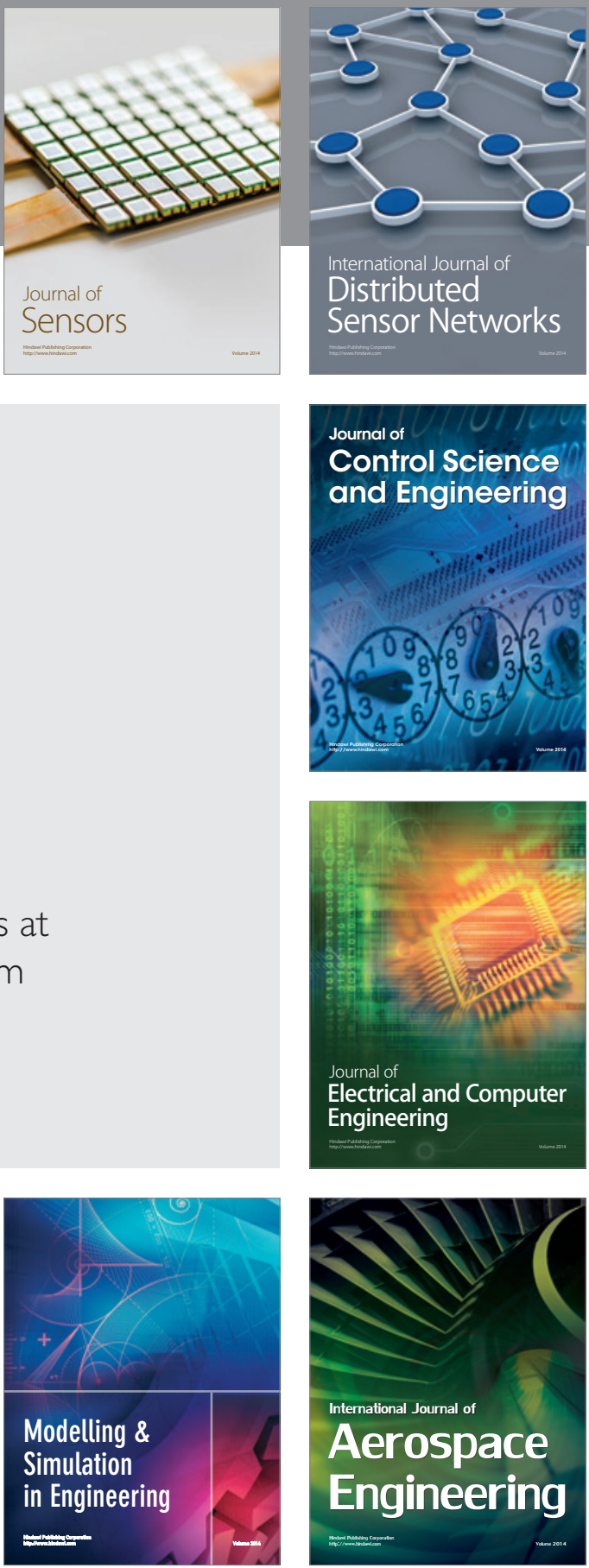

Journal of

Control Science

and Engineering
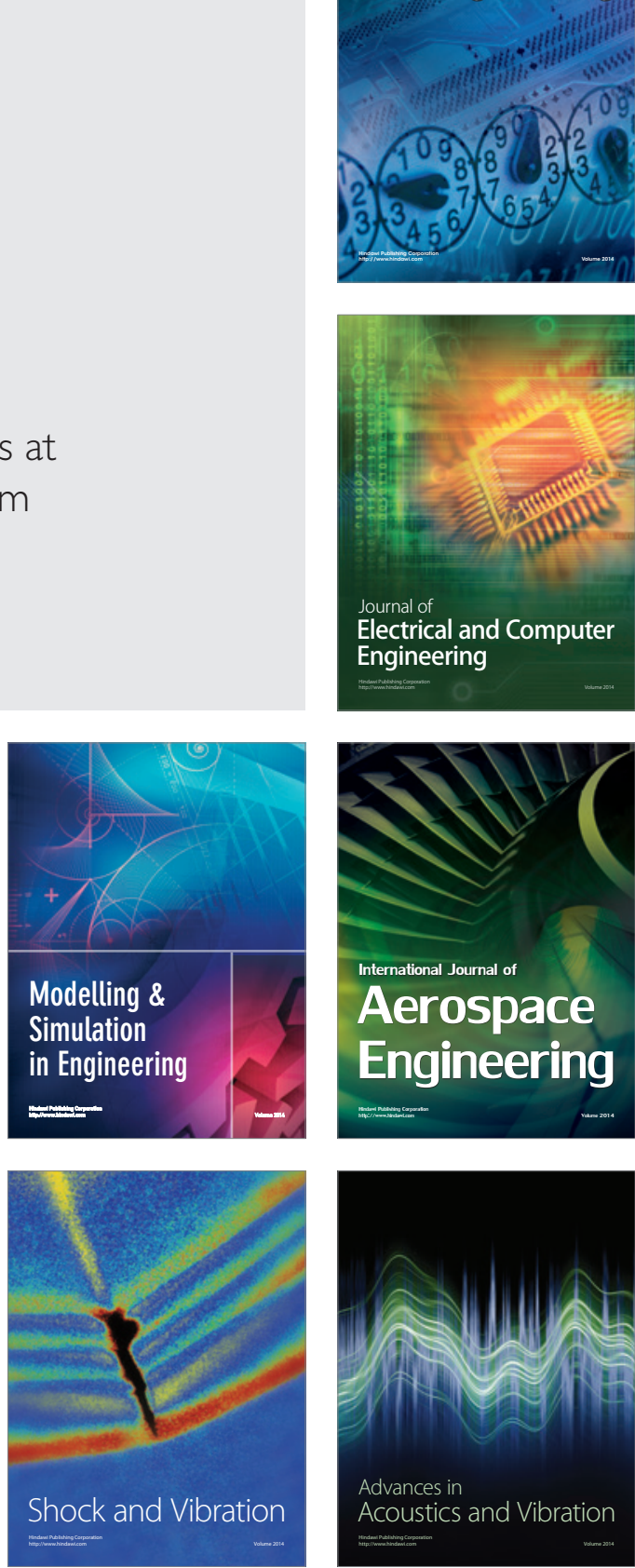